\title{
OPERATIONAL SAFETY AND OPERATOR MANAGEMENT TO ENABLE THE USE OF UNMANNED AIRCRAFT SYSTEMS (UAS) AS GEOMATICS TOOLS
}

\section{SEGURIDAD OPERACIONAL Y GESTIÓN DEL OPERADOR PARA HABILITAR EL USO DE SISTEMAS AÉREOS NO TRIPULADOS (UAS) COMO HERRAMIENTAS GEOMÁTICAS}

\author{
Norberto Vera*, Israel Quintanilla, Jordi Vidal, Beatriz Fernández
}

Department of Cartographic Engineering, Geodesy and Photogrammetry, Universitat Politècnica de València, Camino de Vera s/n, 46022 Valencia, Spain. norvevle@doctor.upv.es; iquinta@cgf.upv.es; jorviul@fiv.upv.es; beaferga@topo.upv.es

\begin{abstract}
:
Potential civil applications of Unmanned Aircraft Systems (UAS), commonly known as drones, have risen steeply during the last decade, mainly due to their versatility and capability of spatial data gathering. Nonetheless, real use of UAS is quite restricted nowadays, primarily due to safety and regulatory constraints. This multidisciplinary project aims to perform specific safety assessments using the SORA methodology adopted by the European Aviation Safety Agency (EASA) and develop documentation and procedures for operators to follow, complying with all required safety and regulatory requirements. As a result, DEURPAS-UPV is the first Spanish drone operator belonging to a university to be authorized by Spanish civil aviation agency (AESA-Agencia Estatal de Seguridad Aérea), to perform drone flights in urban areas, in controlled airspace and during the night. In addition, DEURPAS-UPV has performed the first authorized experimental transport operations using drones in Spain. The results from safety assessment and designed procedures have been successfully applied to the operation of Safety and Emergency service providers, such as Valencia Local Police Corps and the Valencian Emergency and Safety Response Agency (AVSRE - Agencia Valenciana de Seguridad y Respuesta a las Emergencias). Overall, this project has served as an enabler for more complex and safer UAS operations, from the operator's point of view, which will help break the barriers related to the use of these aircraft, with huge potential in geomatics applications.
\end{abstract}

Key words: UAS, drone, Geomatics, SORA, Operational safety, Emergency

\section{Resumen:}

Las aplicaciones civiles de los sistemas aéreos no tripulados (UAS), comúnmente conocidos como drones, han aumentado considerablemente durante la última década, principalmente debido a su versatilidad y capacidad de recopilación de datos espaciales. Sin embargo, el uso real de los UAS está bastante restringido hoy en día, principalmente debido a las restricciones de seguridad y legislativas. Este proyecto multidisciplinar tiene como objetivo realizar evaluaciones de seguridad específicas utilizando la metodología SORA adoptada por la Agencia Europea de Seguridad Aérea (EASA) y desarrollar documentación y procedimientos para que los operadores los sigan, cumpliendo con todos los requisitos de seguridad y normativos exigidos. Como resultado, DEURPAS-UPV es el primer operador español de drones perteneciente a una universidad que ha sido autorizado por la Agencia Estatal de Seguridad Aérea (AESA), para realizar vuelos con drones en zonas urbanas, en espacio aéreo controlado y durante la noche. Además, DEURPAS-UPV ha realizado las primeras operaciones experimentales de transporte con drones autorizadas en España. Los resultados de la evaluación de seguridad y los procedimientos diseñados se han aplicado con éxito a la operación de proveedores de servicios de Seguridad y Emergencias, como el Cuerpo de Policía Local de Valencia y la Agencia Valenciana de Segurida y Respuesta a las Emergencias (AVSRE). En general, este proyecto ha servido para facilitar operaciones con UAS más complejas y seguras, desde el punto de vista del operador, lo que ayudará a romper las barreras relacionadas con el uso de estas aeronaves, con un enorme potencial en aplicaciones geomáticas.

Palabras clave: UAS, dron, Geomática, SORA, Seguridad operacional, Emergencia

\section{Introduction}

In the last few years, the civil use of Unmanned Aircraft Systems (UAS), commonly named drones, has increased considerably thanks to its great potential and versatility. The ability of UAS to carry a wide assortment of sensing equipment and reach hard to access areas has prompted their adoption in varied professional fields, such as public safety (Cerreta et al. 2020), environment monitoring (Gonçalves et al. 2020) or construction safety (Rodrigues and Bastos 2019).

Among the various sciences in which UAS are currently being integrated, it is important to highlight the role of Geomatics. This transversal science brings together a multitude of disciplines such as photogrammetry, geomorphology, precision agriculture, mapping, or

*Corresponding Author: Norberto Vera, norvevle@doctor.upv.es 
heritage conservation, among others, which use geospatial data as main input. Colomina and Molina (2014) review UAS applications focused on photogrammetry and remote sensing, where UAS allow to increase the accuracy of work and simplify the data collection process, even replacing traditional instruments in some cases.

However, UAS operation comes not without risk. In case of malfunction or mishap, UAS are capable of producing severe injuries to hit people, or even fatalities. Duma et al. (2021) studied the possible harm caused by drone blades. In addition, the airspace is already populated with another aircraft, which have very specific and demanding requirements related to their design, production, and operation. Research has been performed regarding the integration of UAS in a non-segregated airspace, considering separation procedures and mid-air collision (MAC) risk (Clothier et al. 2015; Guan et al. 2020).

Spencer's (2018) review highlighted that a catastrophic accident caused by UAS would pose as a great threat to the drone industry, according to operator's point of view. Because of these safety concerns, as well as the public perception that is linked to them, drone regulations around the globe, which were nonexistent until the civil use of UAS flourished, have been very strict.

UAS operations are generally only permitted in a given set of scenarios and specific permissions are generally needed, until the safety of more complex operations can be guaranteed. According to Rango and Liberte (2010), strict regulations limit the range and type of operations to be performed, as well as increasing the workload of operators due to the authorization and registry procedures that must be followed.

During the last years, many authors have proposed risk assessment models to address the risk posed by UAS operations. Luxhøj (2015) proposed the use of ASRM (Aviation System Risk Model) to address the MAC chance, as well as the probability of conflict with other aircraft. Fang et al. (2018) proposed an UAS architecture to enable safer operations beyond line of sight of the pilot. Hammer et al. (2017) presents a failure tree model to assess UAS risk.

All these methodologies have a common point: they are heavily focused on the aircraft, not giving much importance to the operational environment. Looking for a more holistic approach, JARUS proposed the SORA (Specific Operations Risk Assessment) methodology, which is operation centric. SORA allows the assessment of an operation's risk based on its ConOps (the description of the operations parameter's) rather than focusing on the actual aircraft model used. As output, a given set of mitigation measures that would reduce risk to an acceptable level is identified. SORA has been accepted as a standard methodology to assess UAS operations risk, adopted by the European Union. However, its use is not straightforward. Research papers have been publishing regarding the application of SORA to a given ConOps (Capitan et al. 2019), while others focus on how to actually achieve compliance with mitigation measures identified by SORA (Cain et al. 2021). Given that SORA is still in development, others efforts are made to improve it, such as Denney et al. (2018) who propose a more cuantitative approach to
SORA process, which is for the moment based on a qualitative approach.

The objective of this paper is to break the regulatory barrier that limits the use of UAS in R\&D operations, specially in the field of geomatics. For that purpose, the risk of operations of interest will be assessed using a strandardized model. Using the risk assessment result as an input, an operator procedimental and documentary model, compliant with applicable regulation, will be developed, in order to obtain the required authorizations to perform desired operations. After obtaining the authorization, the model has been applied to real life operators, and flights have been performed in scenarios that would otherwise not be possible.

The structure of this paper goes as follows: in section 2 we explain the UAS regulatory frame, and in section 3 we describe the operator model developed to comply with these regulations. Section 4 details the implementation of the model in real remote operators. In section 5 we discuss the results we obtained, and section 6 contains a brief conlusion and highlights future work lines.

\section{UAS regulatory frame}

In this section we will briefly explain the evolution of the regulatory frame for UAS in Spain, including the currently in force European regulation, focusing on the requirements for operators and the allowed flight conditions.

\subsection{Ley $18 / 2014$}

UAS regulation in Spain was unexistent until 'Ley $18 / 2014$ ', which, among a set of measures to improve economic competitivity, included a single article detailing the approved conditions for UAS operations, which would be in force until a UAS specific regulation was published.

The set conditions were quite restrictive, only allowing operations to be performed in very low risk scenarios, such as rural areas in uncontrolled airspace. Flight was limited to Visual Line of Sight (VLOS) conditions, with the exception of aircraft lighter than $2 \mathrm{~kg}$ operating under NOTAM (a public notice to other airspace users). In addition, this law required operators to perform safety assessments and to have an Operating Manual (OM), even if the operation's risk was low.

\subsection{Real Decreto $1036 / 2017$}

The first Spanish specific regulation for UAS was published by the end of 2017 , under the name of 'Real Decreto 1036/2017'.

The basic aspects from previous regulation are largely kept (limited operational conditions and requierements for the operators) for entities operating under an operational declaration. In addition, a new set of operational scenarios is allowed under an authorization from Spanish Civil Aviation Agency, AESA, after checking a set of documents provided by the operator. These scenarios included night flight, urban operations and flight in controlled airspace, widening the UAS use possibilities. In addition, operations Beyond Visual Line of Sight of the pilot (BVLOS) for aircraft heavier than $2 \mathrm{~kg}$ were possible under an authorization, given they were performed in segregated airspace or the aircraft equipped approved 
Detect \& Avoid means. Transport operations were not allowed under normal circumstances. In addition, general exceptions are considered for police operators, and minor exceptions exist for operations performed during public emergency, allowing a less restricted use in case of need.

The methodology proposed by JARUS for assessing UAS risk operations, SORA, was adopted as the Acceptable Means of Compliance (AMC) to perform safety assessments when applying for an authorization. Operations performed in controlled airspace required the coordination of the safety assessment with the designated Air Transit Service Provider (ATSP).

However, the authorization procedure was very strict, designed in accordance to manned aviation safety culture. As a result, the number of authorized operators was low. According to AESA publication of declared operators and authorizations, by the end of 2019 only about $0.5 \%$ of declared operators had been granted an authorization.

\subsection{EU UAS regulation}

During the last few years, the European Aviation Safety Agency, EASA, has been actively working on the development of a common regulatory frame for all Member States (MS), which entried into force on December 31, 2020.

This regulatory frame is defined as operation-centric and risk-based, and clearly differences operational limitations and requirements for operators based upon the risk of the operations, which are classified as Open, Specific or Certified, according to increasing level of risk.

Under this regulatory frame, operator requirements are directly proportional to the operation category. In Open, operators do not need operational declarations nor authorizations to operate, and no $\mathrm{OM}$ is required, but operations are limited to VLOS conditions under a set of three subcategories, allowing a restricted use in urban scenarios.

The scope of Specific category is much wider, where lower-risk, standardized operations can be performed under an operational declaration, and more complex operations are subject of an authorization from the competent authority. Examples of operations performed under an authorization include key expected commercial operations, such as BVLOS delivery over urban areas. All operators performing flights in Specific category are required to have an OM, which will be checked by the competent authority upon authorization application, along with an operational risk assessment performed using SORA methodology.

Current regulation focused on Open and Specific categories. Detailed regulation regarding Certified category is expected to be published during the following years. Certified category roughly corresponds to high-risk operations such as transport of people, overflight of assemblies of people (except for very small aircraft) or transport of dangerous goods.

\section{Development of UAS operator model}

In this research, we have developed a UAS operator model compliant to the requirements of regulations RD1036 and the recent EU regulation.
However, the process we followed is not a straightforward interpretation of the regulations. Instead, we took the safety approach, and we leveraged the early adoption of SORA methodology by AESA as cornerstone, using the output from SORA to establish the foundations of the operator structure.

\subsection{Use of SORA methodology}

SORA, standing for Specific Operations Risk Assessment, is a methodology developed by JARUS to evaluate the risk of operations, using a ConOps (the operating scenario) as input. The SORA process identifies ground and air scenarios based on standardized categories with an assigned intrinsic risk level, named GRC (Ground Risk Class) and ARC (Air Risk Class) respectively. Optional mitigation measures can be considered to reduce GRC (e.g., the use of a parachute) and/or ARC (e.g., operating in time frames when air traffic is lower). Then, tactical mitigations to address the residual risk are accounted for, whose nature depends on the operation being performed in VLOS or BVLOS conditions. A SAIL (Specific Assurance \& Integrity Levels) value is obtained from the combination of final GRC and ARC levels. The SAIL value is an identifier of the overall risk level of the operation, being I-II considered as low risk, IIIIV medium risk and V-VI high risk. Directly linked to the SAIL value, a set of threat mitigation measures, named OSOs (Operational Safety Objectives) is identified. Depending to the level of robustness (low-medium-high) required for each of the 24 OSOs (increasing with SAIL), a set of requirements must be fulfilled. In addition, considerations regarding adjacent air and ground areas are taken into account, addressing the possibility of a containment failure (i.e., the aircraft flying outside of the approved operational volume).

Demostrating compliance with higher-than-two SAIL values requires fulfilment of medium to high robustness measures, which are related to very demanding aeronautical standards, generically out of the generic UAS operator's reach. Terkildsen and Jensen (2019) assessed compliance of several DJI (the main civil UAS manufacturer worldwide) models, none of them complying with SAIL II requirements without the need to perform additional activities. Thus, a set of ConOps limited to SAIL II value was designed, in order to cover most of the intended operations.

Scenarios intrinsically linked to SAIL II, without the application of reductions to GRC and/or ARC, are very limited (e.g., rural areas and uncontrolled airspace). Thus, to achieve a low SAIL value with a greater set of scenarios, we took the following approach: first we identified applications of interes, both in geomatics and other fields of interes, then we assessed ground and air scenarios for these applications and finally we considered the required mitigations that would lower GRC and/or ARC so the final SAIL result is II in these scenarios.

Applications of interest are: photogrammetry, precision agriculture, mapping, heritage, inspections, cadastre, civil engineering, multimedia productions, police operations, firefighting, search and rescue, and medical emergencies. While operations related to agriculture, firefighting or search and rescue are mostly expected to be performed in rural areas, the rest are expected to be performed equally in both urban or rural areas. Regarding the air scenario, both uncontrolled or controlled airspace 
can be found, not depending on the nature of the application but in the specific geographic area it is being performed.

To cover all these scenarios, we considered the riskier option, urban scenario in controlled airspace, and then assessed the required mitigations that would lower GRC and/or ARC so the final SAIL result is II. If demonstration of compliance with the combination of these mitigations is feasible with reasonable means, which worked for VLOS operations, then the ConOps is closed. However, scenarios such as BVLOS operations over urban areas inside controlled airspace, are linked to a high intrinsic risk and the demonstration of compliance with measures to reduce risk to SAIL II level is similar in complexity to achieving compliance with higher-than-two SAIL, which had already been deemed unfeasible for the time being. In these cases, instead of applying reduction of GRC and/or ARC, the base scenario was modified via the deployment of ground-controlled areas and/or segregated airspace, so that no people on the ground or other air traffics are allowed, respectively. This way, risk reduction is achieved via completely removing the threat, at the cost of increased operation planning complexity.

As reference material to perform the safety assessments, we used the AMC developed by AESA, named Apéndice $\mathrm{S}$. Following the established procedure meant a separate authorization process was needed for each scenario, which implied a heavy workload for operators, ATSPs and also AESA.

Thus, a different approach to apply SORA methodology was proposed: instead of considering a single and specific ConOps, we would consider all the possible permutations of a closed set of scenarios. This is feasible because all these scenarios have a common point: an output of SAIL II and the same linked OSO robustness requirements. This way, a safety assessment considering VLOS operations, either in rural or urban areas, in controlled or uncontrolled airspace and during the day or night was developed. The assessment was expanded in comparison to a traditional SORA assessment, via the clear definition of the mitigation measures to be applied in any of seven permutations of the ConOps, having a common SAIL and OSO output. Note that the eighth possible option, the combination of rural areas and uncontrolled airspace, during the day, was ignored as those operations would not require an authorization process via SORA assessment.

Thus, the OSOs requirements for SAIL II were identified as the foundations for the operator documentation pack that defines the operator management model. Of the 24 OSOs identified by SORA, 14 require a low level of robustness, 4 a medium level of robustness (all related to operational procedures) and the rest are optional.

\subsection{Operator documentation pack}

Real Decreto 1036/2017 states that operators need to provide a given set of documents when applying for an authorization. AESA developed a set of AMC and Guidance Material (GM) regarding the reference contents for each of these documents.

We assessed the 18 OSOs to decide in which of these documents should the requirements materialize, either using the same structure provided by $A M C / G M$ or expanding it as necessary.

In order to properly manage the remote operator activities, it was decided that its structure should be divided in three sections: operations acts as the main one, focused on flight planning and execution, while maintenance section is responsible for all aircraft and other equipment to be in adequate conditions. Finally, training section shall monitor remote pilots (and other relevant crew) qualification, ensuring their competence is fit for any operation to be performed. Each section uses a main document as reference, auxiliary documents and a registry, and a responsible person is assigned to assure relevant tasks are performed, as seen in Table 1. In case of small remote operators, responsible functions can be shared by the same person, although it is not recommended.

Table 1: Organizational scheme of a UAS operator.

\begin{tabular}{c|c|c|c} 
Division & Responsible & $\begin{array}{c}\text { Main } \\
\text { Document }\end{array}$ & Registry \\
\hline Operations & $\begin{array}{c}\text { Operations } \\
\text { Manager }\end{array}$ & $\begin{array}{c}\text { Operations } \\
\text { Manual }\end{array}$ & $\begin{array}{c}\text { Operations } \\
\text { Registry }\end{array}$ \\
Manteinance & $\begin{array}{c}\text { Manteinance } \\
\text { chief } \\
\text { Training }\end{array}$ & $\begin{array}{c}\text { Manteinance } \\
\text { Program }\end{array}$ & $\begin{array}{c}\text { Manteinance } \\
\text { Registry }\end{array}$ \\
& $\begin{array}{c}\text { Training } \\
\text { chief }\end{array}$ & $\begin{array}{c}\text { Training } \\
\text { Program }\end{array}$ & $\begin{array}{c}\text { Training } \\
\text { Registry }\end{array}$
\end{tabular}

\subsection{Adoption of the EU model}

The EU regulatory frame establishes different requirements for operators depending on the operations' category. As Open does not impose any relevant requirements to operators and Certified is still in development, we have focused on adapting to Specific category, where most commercial applications are expected.

Both Specific category and previous Spanish regulation consider a mix of declaration/authorization for operations, following similar procedures. In addition, SORA is adopted by both regulations, the reason why SORA was used as the cornerstone of the model. This way, adaptation can be performed with minimum effort.

However, EU regulatory frame does not require operators to have the documentation pack that we developed, only referencing an OM. Thus, we decided to fuse all the previous documents into a single $\mathrm{OM}$, whose contents were arranged in Parts A, B, C and D (General, Aircraft, ConOps and Training) in a very similar fashion to how traditional manned aviation OM are structured.

\section{Implementation of the operator model}

In parallel to the development of the model, it was gradually implemented in real remote operators, both our operator, DEURPAS-UPV, and public safety and emergency operators, who were considered as prioritary users.

\subsection{DEURPAS-UPV}

In order to validate the developed model, a first authorization was applied for, with a relatively simple ConOps: night flights for R\&D purposes. After a few 
rounds of polishing based on AESA feedback regarding aspects to be corrected, an authorization was issued in November 2019, thus validating the first iteration of the model.

A second authorization application is performed shortly after, using the updated model with the multiple-ConOps SORA assessment, which had been previously coordinated and agreed upon with relevant ATSPs (ENAIRE, SAERCO and FerroNATS). After remediation of minor discrepancies, the authorization was granted by the end of March 2020, fully validating the proposed model.

Under the scope of these authorizations, our operator was capable to perform a wider variety of R\&D operations. However, some operations considered prioritary, such as medical delivery, were still not possible because of regulatory constraints. For that reason, another authorization process was started, this time focusing on applying for exemptions regarding experimental transport flights. Note that the difference between R\&D operations and experimental flights and is subtle: the objective of the former is to capture a set of data (e.g., geospatial information) and perform R\&D activities based on that dataset, while the latter aim to test the way the flights are performed to develop new kinds of operations. This way, safety assessments for BVLOS delivery operations in urban areas were performed, considering controlled ground areas and segregated airspace, and an authorization was applied for. In November 2020, we performed the first experimental flights of this kind in Spain. More information regarding this particular set of flights is detailed in Quintanilla et al. (2021).

By May 2021, thanks to the granted authorizations, DEURPAS-UPV has performed over 70 operations in complex scenarios. A small relevant set of these operations is detailed in Table 2.

Table 2: List of flights performed with their corresponding ConOps.

\begin{tabular}{c|c|c}
$\begin{array}{c}\text { Flight date } \\
(\text { dd/mm/yyyy })\end{array}$ & ConOps & Aircraft \\
\hline $05 / 10 / 2020$ & Night - Controlled & DJI Mavic 2 \\
& $\begin{array}{c}\text { Airspace - Urban - Street } \\
\text { lighting inspection }\end{array}$ & Enterprise \\
$16 / 11 / 2020$ & Controlled Airspace - & DJI Matrice \\
& Urban - Transport & 300 RTK \\
$28 / 03 / 2021$ & Controlled Airspace - & DJI Mavic 2 \\
& Photogrammetry & Enterprise \\
$26 / 04 / 2021$ & Controlled Airspace - & DJI Mavic 2 \\
& Urban - Heritage & Enterprise \\
& Inspection &
\end{tabular}

As a graphical example of these flights, Figure 1 corresponds to an aerial image of the tower of Santa Catalina's Church, in Valencia. The objective of this flight was to assess the level of luminic impact of the new public lighting.

In April 2021, operations were performed over Santo Domingo Convent, to assess deterioration of windows and roof tiles, as well as the location of a dove flock that had nested inside the dome, endangering art pieces inside the facility (Fig. 2).

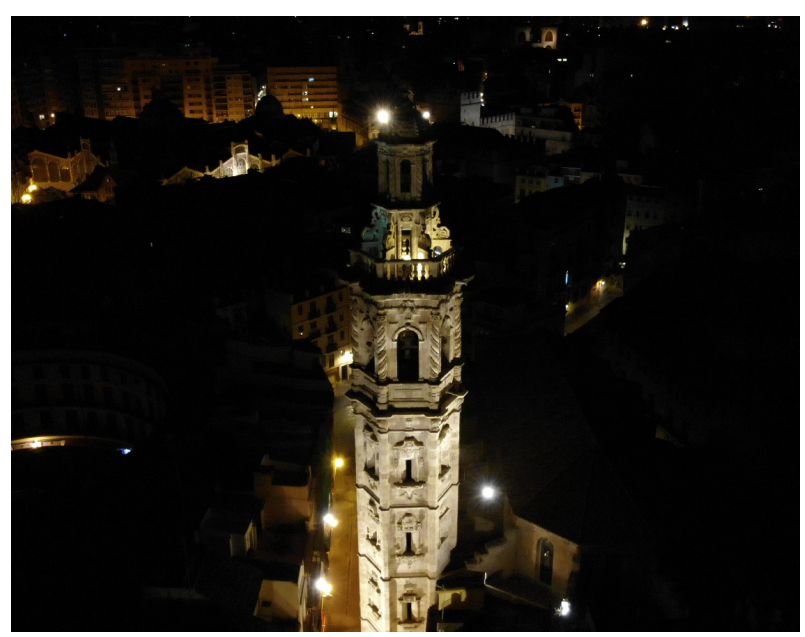

Figure 1: Public light inspection at Santa Catalina's Church, Valencia

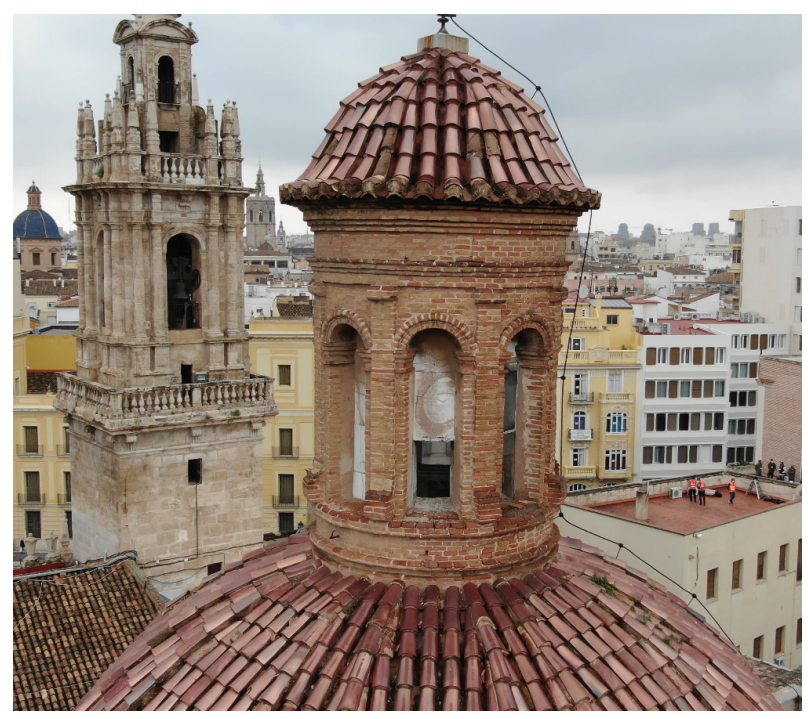

Figure 2: Detail view of the dome of the Santo Domingo Convent, Valencia for heritage inspection.

\subsection{Safety and emergency operators}

In parallel to the validation of the operator model, it was distributed to public safety and emergency entities, such as the Valencian Agency for Safety and Emergency Response (AVSRE) and the local Police Corps of Valencia, and the nearby settlements of Algemesí, Almussafes, Bétera, Culllera, Nules, Picassent, Vall d'Uxò and Xàtiva.

Although Police Corps are exempt from any authorization, and AVSRE used an exemption when operating in public emergency situations, their operations must indeed be performed in safety conditions, considering the appropriate safety mitigation measures. This way, the operator model acts as an underlying way to guarantee the safety of these operations.

\section{Discussion}

The conservative approach followed by approved regulations, based on aeronautical standards has been an obstacle for the development of UAS operations. However, this has also had a positive effect in safety with 
no major UAS incidents reported in Spain during these years.

Evolution of regulations shall also be matched with related AMC \& GM, to ensure operators are able to comply with requirements, and to show such compliance to competent authorities. In the particular case of Spanish regulation, AMC \& GM related to the use of SORA to perform safety assessment were not published until 9 months after the respective regulation, which hindered the authorization processes during that elapsed time. This has been somewhat balanced because, as early adopters of SORA, Spanish operators are already used to this methodology and thus better prepared to adapt to the new European regulatory frame.

According to AESA periodic publication of authorized operators, by the end of February 2020 , only two remote operators belonging to Spanish Universities had been granted an authorization: DEURPAS-UPV, as mentioned before, and CACTI-remote sensing from Vigo university. As public research entities, only FADA (Fundación Andaluza para el Desarrollo Aeroespacial) and Instituto Tecnológico de Canarias are listed.

This gives a perspective point regarding how important it is to develop the operator structure and capabilities, as well as the R\&D techniques that will make use of UAS flights.

SORA methodology is currently in development, applying a primarily qualitative model for the moment. Future versions with a cuantitative approach are expected soon, enhancing the methodology's representativeness. A critical step of the performed research was the coordination of safety assessments with ATSPs, which also apply very restrictive criteria. As SORA is still in development, with some changing parameters and others left to open interpretation, achieving agreement with ATSPs has been a difficult task in the process.

Another aspect to consider is the relatively low risk value of the addressed ConOps, limited to SAIL II values. Additional research work is being done regarding compliance with higher requirements, specially in regard to the aircraft design and manufacturing processes. EASA has recently developed a design verification process, during which operators and manufacturers can demonstrate compliance with SAIL III-IV levels.

\section{Conclusion}

In this paper, an operator management and documentary model, based on the output of SORA assessment has been detailed and proven valid, enabling the realization of complex operations.

The adoption of these models by R\&D entities will stimulate a more widespread, less limited, use of UAS, which will speed up the development of their possible applications.

Work in this field will keep on, continuously adapting to everchanging regulations and the development of new standards and technologies. A special field of interest for the future is the concept of U-Space or UTM, which focuses on the traffic management of unmanned aircraft systems and are expected to enable large numbers of simultaneous operations.

\section{Acknowledgements}

This work was supported by the Generalitat Valenciana under Grant DECRETO 63/2020 and Universitat Politècnica de València under Grant PAID-01-1.

\section{References}

CAIN, S., TORENS, C., JUCHMANN, P., VOLKERT, A., TOMASELLO, F., NATALE, M., and DUCCI, M., 2021. Standards for UAS - acceptable means of compliance for low risk sora operations. In AIAA Scitech 2021 Forum. American Institute of Aeronautics and Astronautics Inc, AIAA, p. 1177. DOI: 10.2514/6.2021-1177

CAPITAN, C., CAPITAN, J., CASTANO, A. R., and OLLERO, A., 2019. Risk assessment based on SORA methodology for a UAS media production application. In 2019 International Conference on Unmanned Aircraft Systems, ICUAS 2019 (pp. 451-459). Institute of Electrical and Electronics Engineers Inc. DOI: 10.1109/ICUAS.2019.8798211

CERRETA, J. S., BURGESS, S. S., and COLEMAN, J., 2020. UAS for public safety operations: A comparison of UAS point clouds to terrestrial LIDAR point cloud data using a FARO scanner. International Journal of Aviation, Aeronautics, and Aerospace, 7(1). DOI: 10.15394/IJAAA.2020.1432

CLOTHIER, R. A., WILLIAMS, B. P., and FULTON, N. L., 2015. Structuring the safety case for unmanned aircraft system operations in non-segregated airspace. Safety Science, 79, pp. 213-228. DOI: 10.1016/j.ssci.2015.06.007

COLOMINA, I., and MOLINA P., 2014. Unmanned aerial systems for photogrammetry and remote sensing: A review. ISPRS Journal of Photogrammetry and Remote Sensing, 92, pp. 79-97, ISSN 0924-2716. DOI: 10.1016/j.isprsjprs.2014.02.013

DENNEY, E., PAI, G., and JOHNSON, M., 2018. Towards a rigorous basis for specific operations risk assessment of UAS. In AIAA/IEEE Digital Avionics Systems Conference - Proceedings (Vol. 2018-September). Institute of Electrical and Electronics Engineers Inc. DOI: 10.1109/DASC.2018.8569475

DUMA, L.A., BEGONIA, M.T., MILLER, B., and DUMA, S.M., 2021. Proposed Injury Threshold for Drone Blade Lacerations. Ann Biomed Eng., 49, pp. 1125-1127. DOI: 10.1007/s10439-021-02759-2

FANG, S. X., O'YOUNG, S., and ROLLAND, L., 2018. Development of small UAS beyond-visual-line-of-sight (BVLOS) flight operations: System requirements and procedures. Drones, 2(2), pp. 1-17. DOI: 10.3390/drones2020013

GONÇALVES, G., ANDRIOLO, U., PINTO, L., and BESSA, F., 2020. Mapping marine litter using UAS on a beach-dune system: a multidisciplinary approach. Science of the Total Environment, 706. DOI: 10.1016/j.scitotenv.2019.135742 
GUAN, X., LYU, R., SHI, H., and CHEN, J., 2020. A survey of safety separation management and collision avoidance approaches of civil UAS operating in integration national airspace system. Chinese Journal of Aeronautics. DOI: 10.1016/j.cja.2020.05.009

HAMMER, J., MURRAY, A. R., and LOWMAN, A., 2017. Safety analysis paradigm for UAS: Development and use of a common architecture and fault tree model. AIAA/IEEE Digital Avionics Systems Conference - Proceedings (Vol. 2017September). Institute of Electrical and Electronics Engineers Inc. DOI: 10.1109/DASC.2017.8102039

LUXHØJ, J.T., 2015. A Socio-technical Model for Analyzing Safety Risk of Unmanned Aircraft Systems (UAS): An Application to Precision Agriculture. Procedia Manufacturing, 3, pp. 928-935. DOI: 10.1016/j.promfg.2015.07.140

QUINTANILLA, I., VERA, N., ALCARAZ, P., VIDAL, J., and FERNANDEZ, B., 2021. A Quickly Deployed and UAS-Based Logistics Network for Delivery of Critical Medical Goods during Healthcare System Stress Periods: A Real Use Case in Valencia (Spain). Drones, 5(1), p. 13. DOI: 10.3390/drones5010013

RANGO, A., LALIBERTE, A. S., 2010. Impact of flight regulations on effective use of unmanned aircraft systems for natural resources applications. Journal of Applied Remote Sensing, 4(1), p. 043539. DOI: 10.1117/1.3474649

RODRIGUES, R., and BASTOS, D., 2019. Integrating resilience engineering and UAS technology into construction safety planning and control. Engineering, Construction and Architectural Management, 26(11), pp. 2705-2722. DOI: 10.1108/ECAM-12-2018-0541

SPENCER, D., 2018. Exploring Impediments to the Proliferation of Commercial Unmanned Aerial System Use in the National Airspace System of the United States. Muma Business Review, 2, pp. 105-121. DOI: 10.28945/4145

TERKILDSEN, K. H., and JENSEN, K., 2019. Towards a tool for assessing UAS compliance with the JARUS SORA guidelines. In 2019 International Conference on Unmanned Aircraft Systems, ICUAS 2019, pp. 460-466. Institute of Electrical and Electronics Engineers Inc. DOI: 10.1109/ICUAS.2019.8798236 